Gut, 1987, 28, 88-92

\title{
Clinical trial
}

\section{Comparative trial of sodium cromoglycate enemas with prednisolone enemas in the treatment of ulcerative colitis}

\author{
R H GRACE, A E GENT, AND M D HELLIER \\ From the Royal Hospital, Wolverhampton, Salisbury General Infirmary, Salisbury, and Princess Margaret \\ Hospital, Swindon, Berks
}

SUMmaRY A double blind multicentre study comparing sodium cromoglycate $(600 \mathrm{mg} / 100 \mathrm{ml})$ by enema with prednisolone $(20 \mathrm{mg} / 100 \mathrm{ml})$ by enema is reported. The study was conducted over a nine week period in the treatment of 70 patients with ulcerative colitis. Analysis of symptoms showed significant decreases in scores for patients in both groups, both at four and eight weeks; the only difference between the two groups was a significantly greater improvement in the reduction of rectal bleeding after four weeks in the prednisolone group. On sigmoidoscopy, both treatment groups showed a highly significant improvement after four and eight weeks with no significant differences being seen between the groups. Histology of the rectal biopsies showed a significant improvement in the inflammation of the mucosa for both treatment groups after four and eight weeks with no differences being observed between the groups. There were no significant changes in eosinophils from baseline and no difference between the groups at four and eight weeks.

Sodium cromoglycate is effective in the treatment of disorders associated with type I hypersensitivity reactions accompanied by mast cell degranulation and its importance in the management of asthma is widely accepted. Because there is evidence of tissue eosinophilia and mast cell activity in some patients with ulcerative colitis, it was thought that sodium cromoglycate might be of value in the management of this disease.

In a four week double blind crossover study against placebo by Heatley et al, ${ }^{1}$ patients with distal proctitis were given sodium cromoglycate, $200 \mathrm{mg}$ by enema twice daily and $100 \mathrm{mg}$ orally three times a day. Fourteen out of 26 patients were said to respond and this response appeared to be in those patients with a high eosinophil count in the initial rectal biopsies. In a further crossover study against placebo (two periods of six months), sodium cromoglycate ( $2 \mathrm{~g} /$ day $)$ given orally to 12 patients, significantly improved patient well being and the sigmoidoscopic and rectal biopsy appearances ${ }^{2}$;

Address for correspondence: Mr R Grace, FRCS, Research Unit, Royal Hospital, Wolverhampton WV2 1BT.

Received for publication 28 April 1986 these patients, however, had mild disease or were in remission.

Further oral studies in larger groups of patients, however, did not confirm these initial results. The relapse rate of patients in remission was significantly higher when maintained on oral sodium cromoglycate than when compared with maintenance on sulphasalazine. ${ }^{34}$ Whilst a similar enema study to that carried out by Heatley has not yet been repeated, oral sodium cromoglycate was shown to be no better than placebo when added to therapy in patients apparently resistant to sulphasalazine and corticosteroids. ${ }^{5}$ In a further oral study ${ }^{6}$ there was no evidence of an improved clinical response in patients with active disease when compared with placebo while neither did it alter the relapse rate of patients with inactive disease. All these studies, however, were carried out in patients under review who had already been given some form of conventional therapy. In view of the apparent early success of sodium cromoglycate in enema form ${ }^{1}$ and because sodium cromoglycate appears to exert its effects in asthma by topical application to the bronchial mucosa, it was felt that it was more likely to be effective in ulcerative colitis in enema form 
than by oral administration. In previous small open studies, we have looked at the clinical response to sodium cromoglycate enemas $(200 \mathrm{mg}, 600 \mathrm{mg}$, and $1000 \mathrm{mg}$ ); sodium cromoglycate $(600 \mathrm{mg} / 100 \mathrm{ml})$ appeared to produce the best clinical response.

In this multicentre study we have compared prednisolone enemas $(20 \mathrm{mg})$ with sodium cromoglycate enemas $(600 \mathrm{mg})$ in patients with distal proctitis and distal colitis; approval was obtained from ethical committees in all three hospitals.

\section{Methods}

\section{PATIENTS}

Seventy patients with ulcerative colitis diagnosed on the basis of clinical history, sigmoidoscopic findings and rectal biopsies were studied. Informed consent was obtained from all patients before entry into the study. Two groups of patients were admitted to the study and were classified as: - (i) Distal proctitis that is, a normal vascular pattern was apparent on sigmoidoscopy above the upper limit of the disease. (ii) Distal colitis - the abnormality extended above $25 \mathrm{~cm}$ on sigmoidoscopy but an instant barium enema showed no abnormality proximal to the splenic flexure.

Both new patients and old patients previously in remission, presenting with a relapse, were admitted to the study.

\section{DESIGN OF THE STUDY}

Each patient was assigned randomly to receive double blind treatment with either sodium cromoglycate enemas $(600 \mathrm{mg} / 100 \mathrm{ml}$ water $)$ or prednisolone sodium phosphate enemas $(20 \mathrm{mg} / 100 \mathrm{ml}$ water), twice daily for four weeks after an initial baseline period of one week; if the clinical progress was satisfactory, the enemas were then reduced to once a day for a further four weeks. Patients in relapse already on maintenance sulphasalazine continued on the same dose. The enemas were packed in identical bags.

\section{PATIENT ASSESSMENT}

Patients were assessed at presentation, during a baseline period of one week, and then at four and eight weeks after treatment started. Assessment related to: (1) symptoms recorded on a diary card. (2) The appearances on sigmoidoscopy: (3) Rectal biopsy.

\section{RECTAL BIOPSY}

The rectal biopsies were fixed on gauze in $10 \%$ formal saline and then processed into wax blocks. Sections were cut at $5 \mu$ from these blocks and stained with haematoxylin and eosin, periodic acid-
Schiff/Alcian Blue (for mucopolysaccharides), and Carbol Chromotrope (for eosinophils). All the biopsies were examined by an independent pathologist without knowledge of the treatment given and were graded as follows: - Grade 0 - inactive/ quiescent; grade 1 - slight activity, grade 2 moderate activity: grade 3 - severe activity. This grading was based principally upon neutrophil exudate and goblet cell depletion. The numbers of eosinophils per square $\mathrm{mm}$ in the lamina propria were also counted.

\section{ANALYSIS OF RESULTS}

The Mann-Whitney U Test was used to compare the two groups, both at presentation and during the baseline period and after treatment for four and eight weeks; within treatment group comparisons after four and eight weeks with baseline were made using a Wilcoxon's match-pairs signed/ranks test. A $5 \%$ two-tailed significance level was used in all tests.

\section{Results}

Seventy patients (Table 1) were admitted to the study with 35 patients in each group. Twenty seven patients were men and 43 women with ages ranging

Table 1 Patient characteristics

\begin{tabular}{|c|c|c|c|}
\hline & & $\begin{array}{l}\text { Sodium } \\
\text { cromoglycate }\end{array}$ & $\begin{array}{l}\text { Prednis- } \\
\text { olone }\end{array}$ \\
\hline \multicolumn{4}{|l|}{ Sex } \\
\hline & Men & 13 & 14 \\
\hline & Women & 22 & 21 \\
\hline \multicolumn{4}{|l|}{ Presentation } \\
\hline & First attack & 22 & 24 \\
\hline & Relapse & 13 & 11 \\
\hline \multicolumn{4}{|c|}{$\begin{array}{l}\text { Duration of discase } \\
\text { (new patients) }\end{array}$} \\
\hline & $0-12$ weeks & 8 & 6 \\
\hline & 13-24 weeks & 5 & 4 \\
\hline & 24 weeks-1 year & 4 & 7 \\
\hline & 1 ycar + & 4 & 6 \\
\hline \multicolumn{4}{|c|}{$\begin{array}{l}\text { Duration of disease } \\
\text { (relapse patients) }\end{array}$} \\
\hline & years $<2$ & 3 & 1 \\
\hline & $2-5$ & 4 & 6 \\
\hline & $6-10$ & 1 & 1 \\
\hline & $11-20$ & 4 & 2 \\
\hline & $>20$ & 1 & 1 \\
\hline \multicolumn{4}{|l|}{$\begin{array}{l}\text { Salazopyrine } \\
\text { (rclapse) }\end{array}$} \\
\hline \multirow{2}{*}{\multicolumn{3}{|c|}{ Extent of disease }} & 11 \\
\hline & & & 12 \\
\hline & Distal Colitis & 19 & 22 \\
\hline \multicolumn{4}{|l|}{ No. each centre } \\
\hline & Wolverhampton & 14 & 14 \\
\hline & Salisbury & 11 & 12 \\
\hline & Swindon & 10 & 9 \\
\hline
\end{tabular}


from 18-78 years (mean 40 years). On entry, 29 patients had distal proctitis (16 sodium cromoglycate: 13 prednisolone) while 41 patients had distal colitis (19 sodium cromoglycate: 22 prednisolone). Forty six patients were having their first attack while 24 were in relapse after remission. Forty five patients had no pretrial maintenance therapy. Twenty two patients were already on sulphasalazine and continued to take their maintenance dose. The remaining three patients who had previously taken steroids, mistakenly took some during the study and were excluded from the efficacy analysis. Three further patients were also withdrawn; one in the prednisolone group because of non-cooperation and one in each treatment group at the end of one month because of treatment failure.

\section{SYMPTOMS}

\section{(a) Stool frequency (Table 2)}

The percentage of patients with two stools or less per day was $16 \%$ at baseline increasing to $58 \%$ and $64 \%$ at four and eight weeks respectively for the sodium cromoglycate group. Comparable figures for the prednisolone group were $31 \%$ at baseline increasing to $91 \%$ and $84 \%$ at four and eight weeks respectively.

In the sodium cromoglycate group, the mean improvement from the baseline value of $4.9 / 24$ hours was -1.2 at four weeks $(\mathrm{p}<0.05)$ and $-2 \cdot 3$ at eight weeks $(p<0 \cdot 001)$; in the prednisolone group the mean improvement $(p<0.001)$ from the baseline value of $3.5 / 24$ hours was -1.8 and -1.7 at four and eight weeks respectively.

There was no significant difference between the two groups at baseline, at four or at eight weeks.

(b) Rectal bleeding (Table 2)

The percentage of patients with rectal bleeding was $88 \%$ at baseline decreasing to $58 \%$ and $37 \%$ at four and eight weeks respectively for the sodium cromoglycate group. Comparable figures for the prednisolone group were $94 \%$ at baseline decreasing to $7 \%$ and $10 \%$ at four and eight weeks respectively.

Using the scoring scale indicated in Table 2, significant $(p<0.001)$ improvements were seen in both groups. In the sodium cromoglycate group the mean improvement from the baseline value of 1.64 was -0.81 and -0.98 at four and eight weeks respectively; in the prednisolone group the mean improvement from the baseline value of 1.66 was -1.40 and -1.24 at four and eight weeks respectively.

There was a significant difference between the two groups at four weeks favouring prednisolone $(\mathrm{p}<0 \cdot 05)$.

\section{SIGMOIDOSCOPY (Table 2)}

On sigmoidoscopy, none of the patients in either group had a normal mucosa at baseline. After four weeks, $22 \%$ of patients in the sodium cromoglycate

Table 2 Bowel frequency/24 hours, rectal bleeding, improvement on sigmoidoscopy and rectal biopsies

\begin{tabular}{|c|c|c|c|c|}
\hline \multirow[b]{2}{*}{ Variable } & \multirow[b]{2}{*}{ Periods } & \multirow{2}{*}{$\begin{array}{l}\text { Sodium cromoglycate } \\
\text { group }\end{array}$} & \multirow{2}{*}{$\frac{\text { Prednisolone group }}{\text { Mean (sample size) }}$} & \multirow{2}{*}{$\begin{array}{l}\text { Significance of } \\
\text { between treat- } \\
\text { ment comparison }\end{array}$} \\
\hline & & & & \\
\hline & Bascline & $4 \cdot 9(32)$ & $3 \cdot 5(35)$ & $0 \cdot(05<\mathrm{p}<0 \cdot 10$ \\
\hline $\begin{array}{l}\text { Bowel } \\
\text { frequency } 24 \text { hours }\end{array}$ & $\begin{array}{l}\text { Change at: } \\
\text { Visit } 4 \\
\text { Visit } 5\end{array}$ & $\begin{array}{l}-1 \cdot 2(31)^{*} \\
-2 \cdot 3(28)^{\dagger}\end{array}$ & $\begin{array}{l}-1 \cdot 8(34) \dagger \\
-1.7(32)^{\dagger}\end{array}$ & $\begin{array}{l}p>0 \cdot(05 \\
p>0 \cdot(05\end{array}$ \\
\hline Rectal & $\begin{array}{l}\text { Bascline } \\
\text { Change at: }\end{array}$ & $1 \cdot 64(32)$ & $1 \cdot 66(35)$ & $p>0.05$ \\
\hline blceding & $\begin{array}{l}\text { Visit } 4 \\
\text { Visit } 5\end{array}$ & $\begin{array}{l}-0.81(31) \dagger \\
-0.98(30) \dagger\end{array}$ & $\begin{array}{l}-1.40(34) \dagger \\
-1.24(33) \dagger\end{array}$ & $\begin{array}{l}p>0 \cdot(05 \\
p>0 .(05\end{array}$ \\
\hline Improvement on & $\begin{array}{l}\text { Bascline } \\
\text { Change at: }\end{array}$ & $3 \cdot 05(32)$ & $3 \cdot 16(35)$ & $p>0.05$ \\
\hline sigmoidoscopy & $\begin{array}{l}\text { Visit } 4 \\
\text { Visit } 5\end{array}$ & $\begin{array}{l}-1.50(32) \dagger \\
-1.90(29) \dagger\end{array}$ & $\begin{array}{l}-1 \cdot 88(33) \dagger \\
-2 \cdot(09(33) \dagger\end{array}$ & $\begin{array}{l}0.01<p<0.05 \\
p>0 \cdot 05\end{array}$ \\
\hline Rectal & $\begin{array}{l}\text { Bascline } \\
\text { Change at: }\end{array}$ & $1.81(27)$ & $1 \cdot 56(32)$ & $p>0.05$ \\
\hline biopsies & $\begin{array}{l}\text { Visit } 4 \\
\text { Visit } 5\end{array}$ & $\begin{array}{l}-0.52(25) \ddagger \\
-0.52(23)^{*}\end{array}$ & $\begin{array}{l}-0.54(28) \ddagger \\
-0.68(28) \ddagger\end{array}$ & $\begin{array}{ll}p>0.05 \\
p>0.05\end{array}$ \\
\hline
\end{tabular}

Significance of change from baseline: ${ }^{*} p<0 \cdot(05 ., p<0 \cdot(0) 1, \ddagger p<0 \cdot(0)$. $§$ Visits 4 and 5 after four weeks and eight weeks of treatment respectively.

Scoring Scales: Rectal blecding: $0=$ None, $1=$ occasional, $2=$ with every stool. $3=$ alone (no stool)

Sigmoidoscopy: $0=$ normal mucosa, $1=$ loss of normal vascular pattern, $2=$ granular mucosa, $3=$ granular and friable mucosa, $3=$ granular friable mucosa with spontancous blecding.

Biopsy grade: $0=$ inactive/quiescent. $1=$ slight activity, $2=$ moderate activity. $3=$ severe activity. 
group had normal mucosa compared with $42 \%$ in the prednisolone group and after eight weeks these percentages had increased to $44 \%$ and $52 \%$ respectively.

Using the scoring scale indicated in Table 2, significant $(p<0.001)$ improvements were seen in both groups. In the sodium cromoglycate group the mean improvements of the appearance on sigmoidoscopy from the baseline value of 3.05 was -1.50 and -1.90 at four and eight weeks respectively; in the prednisolone group the mean improvement from the baseline value of 3.16 was -1.88 and -2.09 at four and eight weeks respectively.

There was no significant difference between the two groups at baseline, at four or at eight weeks.

RECTAL BIOPSIES (Table 2)

The percentage of patients graded with slight activity or inactive/quiescent on rectal biopsies was $41 \%$ at baseline increasing to $60 \%$ and $70 \%$ at four and eight weeks respectively for the sodium cromoglycate group. Comparable figures for the prednisolone group were $56 \%$ at baseline increasing to $71 \%$ and $75 \%$ at four and eight weeks respectively.

Using the scoring scale indicated in Table 2, the mean improvement in rectal biopsy from the baseline value of 1.81 was -0.52 at four weeks $(p<0.01)$ and -0.52 at eight weeks $(p<0.05)$ in the sodium cromoglycate group; in the prednisolone group the mean improvement $(\mathrm{p}<0.01)$ from the baseline value of 1.56 was -0.54 and -0.68 at four and eight weeks respectively.

There was no significant difference between the two groups at baseline, at four or at eight weeks.

There were no significant changes in the eosinophil count from baseline to those at four and eight weeks; there were no significant differences between the two groups.

\section{Discussion}

It is accepted that steroid enemas are very successful in the initial management of patients presenting with distal disease; the potential value of sodium cromoglycate in distal disease therefore needs to be measured against this success and it is for this reason that we compared sodium cromoglycate enemas against prednisolone enemas rather than a control group.

The initial encouraging results with sodium cromoglycate $^{12}$ have not yet been confirmed although the use of sodium cromoglycate in the management of ulcerative colitis was widely advocated. Heatley ${ }^{1}$ used sodium cromoglycate in enema form and in view of its known topical action on bronchial mucosa, it is not unreasonable to suppose that sodium cromoglycate will also exert its effect by topical action on the rectal and colonic mucosa. The concentration required in the lumen of the large bowel to produce a therapeutic effect in ulcerative colitis is not known but it is possible that this is not reached when sodium cromoglycate is taken orally and it is for this reason that the subsequent studies, none of which used sodium cromoglycate in enema form, failed to produce a therapeutic response.

This study has again shown that steroid enemas are successful in the management of patients presenting with distal disease. In this study, however, it has also been shown that sodium cromoglycate exerts a comparable therapeutic effect in distal disease when given in enema form at a dose of $600 \mathrm{mg} / 100 \mathrm{ml}$. When compared with prednisolone enemas, in relation to improvement in stool frequency, rectal bleeding, sigmoidoscopy and rectal biopsy, the only significant difference between the two groups was a greater improvement in the reduction of rectal bleeding at four weeks in the prednisolone group.

In contrast with Heatley et al, ${ }^{1}$ who found a poor correlation between mucosal inflammatory reaction, based on eosinophil counts in the lamina propria, and changes in the clinical responses and sigmoidoscopic appearance, both treatment groups in this study have shown a good correlation between clinical and histological improvement. In this study the eosinophil counts were not significantly changed from baseline by either treatment and no differences were observed between treatments.

In conclusion, this study has shown that the efficacy of sodium cromoglycate administered as an enema $(600 \mathrm{mg} / 100 \mathrm{ml})$ for eight weeks is comparable with that of prednisolone. Although prednisolone is an established and accepted therapy for the treatment of distal colitis, some patients do not respond and the clinical value of sodium cromoglycate may lie within this group. In addition, the use of prednisolone enemas does lead to the absorption of significant amounts of steroid, ${ }^{78}$ although evidence for suppression of adrenocortical response is not strong. Sodium cromoglycate enemas have no known side effects and their use would avoid the complications which may arise from the long term use of steroids.

We wish to thank Dr Albert Chambers and Mrs J C V Scott of Fisons R \& D Laboratories, who helped in setting up the coded trial and in the statistical analysis of the results. We also wish to thank the Pathology Department of Fisons and Dr Ian Talbot of the Pathology Department, University of Leicester, for the Histopathology. The study was funded by Fisons R \& D Laboratories. 


\section{References}

1 Heatley RV, Calcraft BJ, Rhodes EO, Evans BK. Disodium cromoglycate in the treatment of chronic proctitis. Gut 1975; 16: 559-63.

2 Mani V, Lloyd G, Green FHY, Fox H. Turnberg LA. Treatment of ulcerative colitis with oral disodium cromoglycate. Lancet 1976; 1: 439-41.

3 Dronfield MW, Langman MJS. Comparative trial of sulphasalazine and oral disodium cromoglycate in the maintenance of remission in ulcerative colitis. Gut 1978; 19: 1136-9.

4 Willoughby CP, Piris J, Heyworth MF, Truelove SC. Comparison of disodium cromoglycate and sulphasalazine as maintenance therapy for ulcerative colitis. Lancet 1979; 20: 119-22.
5 Bucknell NA, Gould SR, Day DW, Lennard-Jones JE, Edwards AM. Controlled trial of disodium cromoglycate in chronic persistent ulcerative colitis. Gut 1978; 19: $1140-3$.

6 Binder V, Elsborg L, Greibe J, et al. Disodium cromoglycate in the treatment of ulcerative colitis and Crohns disease. Gut 1981; 22: 55-60.

7 Lee DAH, Taylor GM, Walker JG, James VHT. Plasma prednisolone levels and adrenocortical responsiveness after administration of prednisolone-21phosphate as a retention enema. Gut 1979; 20: 349-55.

8 Lee DAH, Taylor GM, Walker JG, James VHT. Rectally administered prednisolone: evidence for a predominantly local action. Gut 1980; 21: 215-18. 